\title{
Harvesting Energy from Pavement - Electromagnetic Approach
}

\author{
Mohammadreza Gholikhani ${ }^{1, *}$, Seyed Amid Tahami ${ }^{1}$, and Samer Dessouky ${ }^{1}$ \\ ${ }^{1}$ Department of Civil and Environmental Engineering, University of Texas at San Antonio, San Antonio, TX 78249
}

\begin{abstract}
Roadway pavements have a great potential to be a renewable energy source. Because they are continuously subjected to solar radiation and kinetic energy from passing vehicles. In this study, a prototype was developed to harvest passing vehicle kinetic energy by using electromagnetic technology. The prototype was fabricated by mechanical components including top plate, racks, pinions, one-way clutches, shafts, compression springs and generator. The prototype uses deflection generated by passing vehicles and converts it to rotations in shaft that triggers an embedded generator. A performance of the prototype in generating electrical power was evaluated with laboratory tests by using UTM and simulating traffic conditions. The output powers were measured by different magnitudes of the loads, times of loading and times of unloading. The experimental results show promising in generating power by the proposed prototype with a maximum average power of 3.21 mWatt.
\end{abstract}

\section{Introduction}

According to the International Energy Agency, nonrenewable fossil fuels are the main resources of energy production [1], which have several disadvantages such as environment pollution, emission of greenhouse, gases energy crisis and depleting quickly [2]. So, it is necessary to change the paradigm of energy production and develop renewable energy resources. Capturing unused ambient energy and converting it to a more useful form of energy, energy harvesting, is promising source of energy [3]. Roadways and transportation infrastructure, by covering considerable part of urban and rural areas, have a potential to be sources of energy harvesting [3].

Roadway pavements are subjected to different types of energy includes solar radiation and trafficinduced stresses [4]. Roadways require infrastructure utilities such as lighting and signage to operate properly and improve service level of the transportation sector [5]. Energy harvesting in roadways can supply energy for operation of infrastructure, specifically in remote areas [6].

Two main technology groups are being utilized to harvest energy from solar radiation and kinetic energy in pavement. These two groups include different technologies such as thermoelectric systems, piezoelectric materials, solar panel installed in the pavement, electromagnetic systems, and etc. Researchers in this study, previously conducted a study to evaluate a thermoelectric energy harvesting device $[7,8]$. In this technology, the device absorbs the heat of pavements generated by solar radiations to produce power independently of traffic loading. As a result, this technology can solve energy problem for roadways infrastructure and pavement temperatures distress such as rutting simultaneously [8]. They also help to reduce Urban Heat Island effect by controlling temperatures of pavements [7]. The authors also studied piezoelectric technology in pavement [9-13]. Piezoelectric materials use applied stress from traffic loading in pavements to produce electric voltage. Results of these studies suggested that piezoelectric technology is a practical energy resource for low-power facilities of roadways.

Recently, researchers focus on electromagnetic technology to capture passing vehicles' kinetic energy. This technology showed acceptable performances in harvesting energy from vehicle suspensions [14], ocean waves [15-17] and railroads [18-20]. So, its feasibility in roadways has been investigated.

\footnotetext{
*Corresponding author: mohammadreza.gholikhani@utsa.edu
} 
The electromagnetic technology needs to be installed in areas that achieve maximum deflection to generate maximum power. On the other hand, interruption in traffic flow must be avoided. The installation location must serve both of these requirements such as toll station. In addition, speed bumps are used to slow down passing vehicles and reduce risk of accidents [21]. In addition, kinetic energy imposed by vehicles is wasted in speed bumps [22]. So, installation of electromagnetic energy harvesting prototype instead of conventional speed bumps in these areas is logical.

The objective of this study is to introduce an electromagnetic energy harvester. This paper aims to fabricate and test the ability of generating electrical power of prototype under simulated traffic conditions.

\section{Theoretical background}

Electromagnetic technologies work based on Faraday's law. Faraday's law is generalized by the Maxwell-Faraday equation, which states that a timevarying magnetic field will always accompany a spatially electric field, and vice versa [23]. The Maxwell-Faraday equation is:

$$
\nabla \times \mathrm{E}=-\partial \mathrm{B} / \partial \mathrm{t}
$$

Where $\nabla \times$ is the curl operator, $\mathrm{E}$ is the electric field and $\mathrm{B}$ is the magnetic field [24].

\section{Design and mechanism}

When a vehicle passes over the prototype, the vehicle's weight induces kinetic energy resulting in moving internal mechanical components. These components convert the lateral movement of top plate into rotating a shaft inside an embedded generator yielding electrical power [25]. The conversion process of vertical movements caused by vehicle to rotating shafts inside a generator, different types of system components were used including; rack-andpinion system [26], chain and sprockets system [27] and hydraulic power system [28]. In some cases, two systems are combined, for example, a combination of rack, pinion and hydraulic systems [29]. In this study, the rack and pinion were chosen due to its advantages such as simplicity and endurance.

The top plate is the first part of the prototype that is subjected to loads. The material of the top plate was aluminum. The top plate replaces the speed bump, so its profile must be similar to the traditional speed bump. The Convex profile was chosen for this study. The height and maximum displacements of top plate were limited to $75 \mathrm{~mm}$. While, the width of the top plate was $300 \mathrm{~mm}$ and the length of was equal to typical roadway lane width, $3.75 \mathrm{~m}$, to capture passing vehicle, but for the laboratory experiment in this study, the length was reduced to $440 \mathrm{~mm}$ to fit inside the testing equipment.

Next part is rack, which was connected to the top plate to move with it simultaneously. The pinions are connected to the bottom plate with strong support. The rack engages with pinion gears during the top plate vertical movements. These movements are conveyed into rotations of the pinions. These rack and pinion components are made from stainless steel to endure a long service life.

The next part in the prototype is a one-way clutch, which two of them are installed inside the pinions. One-way clutches transmit rotation in only one direction. Which, in this case, the rack and pinion move in two directions, but clutches make it unidirectional rotations and convey just one direction rotation to the shaft. The shaft inside the one-way clutches transfer these unidirectional rotations to an embedded generator. Finally, the generator uses rotations of the shaft and generates electrical power. This power could directly supply power for roadway facilities or be saved in a battery.

Four steel cylindrical supports were installed to hold the prototype structures under vehicle loads. Each support includes one rod that moves inside a hole in the support to guide the top plate to move vertically and limit the top plate to a fixed moving position. Compression springs are placed inside the supports and connected to the top plate to recover the top plate to its origin position after vehicles pass. Figure 1 shows the prototype and its components.

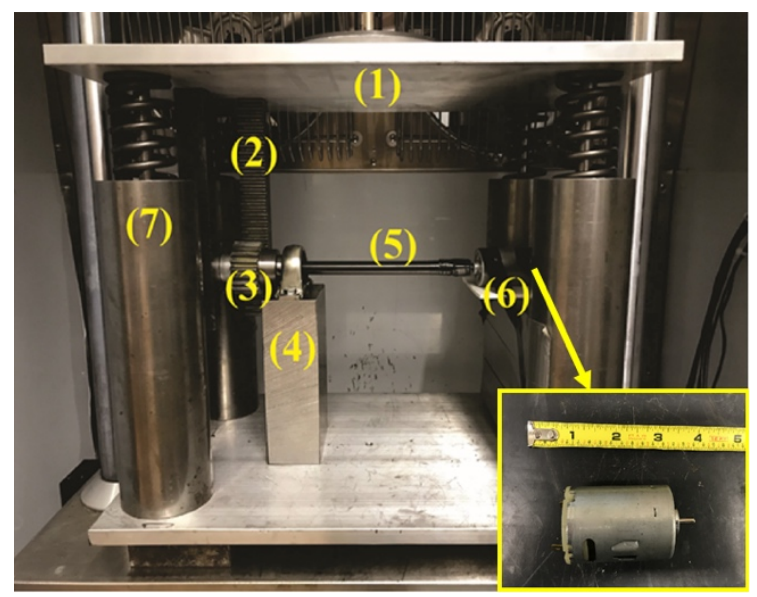

Fig 1. The electromagnetic prototype includes 1) top plate 2) rack 3) pinion and clutch 4) support 5) shaft 6) generator 7) support and spring for top plate. 


\section{Experimental setup and testing}

The Servo-Hydraulic Universal Testing Machine (UTM 25) was used to apply loads to the prototype due to traffic condition. A National Instruments USB Data Acquisition Card, NI DAQ, Multifunction was used to record Voltage and Power of outputs of the generator. The RS-200W resistance substitution box was used as an external resistor.

\subsection{Test procedure}

The experimental tests were executed to study output powers of the prototype under different magnitudes of loads and times of loading. To simulate the traffic loading process, the UTM applied different loads (2, 3 and $4 \mathrm{kN}$ due to small passing vehicle weight) in sinusoidal form. Another variable of the experiment was loading time, and unloading time, which vary based on drivers' behavior in passing speed bumps and following front vehicle. Therefore, two loading cycles of 500 and $1000 \mathrm{~ms}$ and three unloading times; 500,1000 and $1500 \mathrm{~ms}$.

UTM pushes down the top plate in loading time, and aforementioned process in mechanism section happens and the electrical power is generated. Then in unloading time, the UTM allows the top plate to recover its origin position and generates power in return process.

\section{Results and discussion}

Results shows that the pattern of outputs are very close in different loads' magnitudes and loading conditions. As a sample, the output voltages in 12 seconds, is presented in figure 2 .

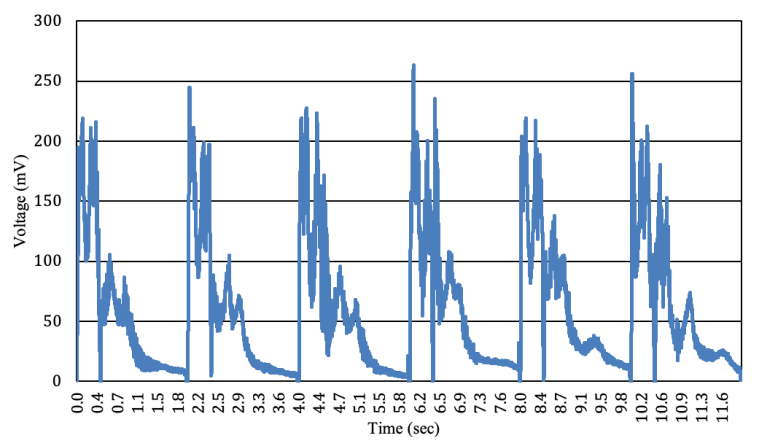

Fig 2. Output voltage in 12 seconds.

Table 1 provides the average output power of the prototype for various conditions in mWatt unit. The values are very small but it is acceptable for new technology with the simplest design and small generator. The output will increase significantly by improving the design. It also can be seen the output powers with different loads are very close, which means that the load is not important factor in this prototype mechanism. Moreover, longer time of loading leads to higher output, which is logical. When the loading time is higher, the deformation is higher and as a result output is higher. Furthermore, unloading time is another factor that affected the output power. By comparing unloading time, cycle time exclude loading time, it can be seen that, smaller unloading time leads to higher output. Because the deformation depends to loading time, so in unloading time, the top plate recovers in shorter time, so the magnetic field varies in shorter time so the prototype generates more power. Both of loading and unloading time are related to vehicle speed. So, the output power depends to passing vehicle too.

Table 1. Average output power (mWatt) under various conditions.

\begin{tabular}{|c|c|c|c|c|}
\hline \multirow{2}{*}{ Cycles time } & \multicolumn{3}{c|}{ Load (kN) } \\
\cline { 3 - 5 } \multicolumn{2}{|c|}{} & 2 & 3 & 4 \\
\hline \multirow{2}{*}{$\begin{array}{c}\text { Loading- } \\
\text { Cycle of } \\
\text { loading and } \\
\text { Unloading } \\
\text { specification }\end{array}$} & $0.5 \mathrm{~s}-1.5 \mathrm{~s}$ & 1.35 & 1.18 & 1.05 \\
\cline { 2 - 5 } & $1 \mathrm{~s}-1.5 \mathrm{~s}$ & 3.21 & 3.19 & 1.57 \\
\cline { 2 - 5 } & $0.5 \mathrm{~s}-2 \mathrm{~s}$ & 0.77 & 0.70 & 0.58 \\
\hline
\end{tabular}

\subsection{Challenges and future work}

The proposed prototype in this study is in its simplest form and as such, it has provided a low voltage output. It is expected that by adding a gearbox and replacing the generator that the output power will increase. The performance of the prototype should be studied under different traffic conditions to optimize the design before its installation in pavements. Another design challenge is ensuring that the design can endure long-term in roadways in order to minimize the maintenance operations.

It worth to notice, more works are ongoing on the prototype with additional components in different conditions and more results will be provided in next publications.

\section{Conclusions}

The electromagnetic energy harvester for scavenging kinetic energy from passing vehicle is proposed. The results from the experimental lab tests show that the technology is a good candidate to be the source of energy for infrastructure of roadways. The lab tests 
were conducted to evaluate power generating ability of the prototype. According to the results, the output power was approximately $3.21 \mathrm{mWatt}$ over each passing axle.

The output values are low because the prototype has the simplest design. Optimizing the design will increase output power significantly. The results also indicated that the amounts of output are connected to the speed of top plate displacements which is directly related to the speed of a passing vehicle speed.

In addition, using this technology to operate signs and lighting in remote areas also improves safety. For instance, the accidents due to the lack of safety facilities can be mitigated. Further study is needed to study the prototype performances under real traffic loads. Also, the effect of implementation of the prototype on a structure of pavement around it should be studied.

The authors would like to acknowledge the financial support from the CPS energy and the Tran-SET Regional University Transportation Center to conduct this research study.

\section{References}

1. Outlook, W.E. (2009). International Energy Agency. Organisation for Economic Cooperation and Development, Paris.

2. Duarte, F. and A. Ferreira (2016). Energy harvesting on road pavements: state of the art. Proc. Inst. Civil Eng. Energy 169(2): 1-12.

3. Morbiato, T., Borri, C., and Vitaliani, R. (2014). Wind energy harvesting from transport systems: A resource estimation assessment. Applied Energy 133, 152-168.

4. Dawson, A., Mallick, R., Hernandez, A.G. and Dehdezi, P.K. (2014). Energy harvesting from pavements. Climate Change, Energy, Sustainability and Pavements, Springer, 481517.

5. Lee, K. and Correia, A. (2010). Investigation of novel methods to harvest solar energy from asphalt pavements, A Research Report to Korean Institute of Construction Technology, University of Rhode Island, Kingston, RI.

6. Wardlaw, J.L., Karaman, I., and Karsilayan, A. (2013). Low-power circuits and energy harvesting for structural health monitoring of bridges. IEEE Sensors Journal 13(2): 709-722.

7. Datta, U. (2016). Harvesting of Thermoelectric energy from asphalt pavements. Master, University of Texas at San Antonio.
8. Datta, U., Dessouky, S., and Papagiannakis, A. (2017). Harvesting Thermoelectric Energy from Asphalt Pavements. Transportation Research Record: Journal of the Transportation Research Board (2628): 12-22.

9. Roshani, H. and Dessouky, S. (2015). Feasibility Study to Harvest Electric Power from Highway Pavements using Laboratory Investigation. Department of Civil and Environmental Engineering University of Texas at San Antonio.

10. Papagiannakis, A., Dessouky, S., Montoya, A., and Roshani, H. (2016). Energy harvesting from roadways. Procedia Computer Science 83, 758765.

11. Roshani, H., Dessouky, S., Montoya, A., and Papagiannakis, A. (2016). Energy harvesting from asphalt pavement roadways vehicleinduced stresses: a feasibility study. Applied Energy 182, 210-218.

12. Papagiannakis, A., Montoya, A., Dessouky, S., and Helffrich, J. (2017). Development and Evaluation of Piezoelectric Prototypes for Roadway Energy Harvesting. Journal of Energy Engineering 143(5): 04017034.

13. Roshani, H., Jagtap, P., Dessouky, S., Montoya, A., and Papagiannakis, A. (2017). Theoretical and Experimental Evaluation of Two Roadway Piezoelectric-Based Energy Harvesting Prototypes. Journal of Materials in Civil Engineering. 30(2): 04017264.

14. Li, Z., Zuo, L., Kuang, J., and Luhrs, G. (2012). Energy-harvesting shock absorber with a mechanical motion rectifier. Smart Materials and Structures 22(2): 025008 .

15. Polinder, H., Damen, M., and Gardner, F. (2005). Design, modelling and test results of the AWS PM linear generator. International Transactions on Electrical Energy Systems 15(3): 245-256.

16. Leijon, M., Danielsson, O., Eriksson, M., Thorburn, K., Bernhoff, H., Isberg, J., Sundberg, J., Ivanova, I., Sjöstedt, E., and Ågren, O. (2006). An electrical approach to wave energy conversion. Renewable energy 31(9): 13091319.

17. Xie, J. and Zuo, L. (2013). Dynamics and control of ocean wave energy converters. International Journal of Dynamics and Control. 1(3), 262-276.

18. Phillips, K.J. (2011). Simulation and control system of a railroad track power harvesting device.

19. Pourghodrat, A. (2011). Energy harvesting systems design for railroad safety. 
20. Wang, J., Lin, T., and Zuo, L. (2013). High efficiency electromagnetic energy harvester for railroad application. ASME 2013 International Design Engineering Technical Conferences and Computers and Information in Engineering Conference, American Society of Mechanical Engineers.

21. Garcia-Pozuelo, D., Gauchia, A., Olmeda, E., and Diaz, V. (2014). Bump modeling and vehicle vertical dynamics prediction. Advances in Mechanical Engineering 6: 736576.

22. Partodezfoli, M., Rezaey, A., Baniasad, Z., and Rezaey, H. (2012). A novel speed-breaker for electrical energy generation suitable for elimination of remote parts of power systems where is near to roads. Journal of Basic and Applied Scientific Research 2(6), 6285-6292.

23. Wang, L., Park, J., Zhou, W., and Zuo, L. (2016). A Large-Scale On-Road Energy Harvester from Highway Vibration. ASME 2016 International Design Engineering Technical Conferences and Computers and Information in Engineering Conference, American Society of Mechanical Engineers.

24. Eom, H.J. (2013). Faraday's Law of Induction. Primary Theory of Electromagnetics, Springer: 95-111.

25. Wang, L., Todaria, P., Pandey, A., O'Connor, J., Chernow, B., and Zuo, L. (2016). An Electromagnetic Speed Bump Energy Harvester and Its Interactions With Vehicles. IEEE/ASME Transactions on Mechatronics 21(4), 1985-1994.

26. Todaria, P., Wang, L., Pandey, A., O'Connor, J., McAvoy, D., Harrigan, T., Chernow, B., and Zuo, L. (2015). Design, modeling and test of a novel speed bump energy harvester. SPIE Smart Structures and Materials+ Nondestructive Evaluation and Health Monitoring, International Society for Optics and Photonics.

27. Aswathaman, V. and Priyadharshini, M. (2011). Every speed breaker is now a source of power. Proc. of 2010 International Conference on Biology, Environment and Chemistry IPCBEE.

28. Obeid, H.H., Jaleel, A.K., and Hassan, N.A. (2014). Design and Motion Modeling of an Electromagnetic Hydraulic Power Hump Harvester. Advances in Mechanical Engineering 6: 150293 .

29. Ullah, K.M., Ahsan-uz-Zaman, K., Hosen, S., Khan, R.H., and Parvin, S. (2016). Electrical power generation through speed breaker. Electrical and Computer Engineering (ICECE), 2016 9th International Conference on, IEEE. 